\title{
PENGEMBANGAN SISTEM E-COUNSELING UNTUK BIMBINGAN DAN KONSELING PERKEMBANGAN ANAK USIA DINI (STUDI KASUS : PAUD PERSADA JEPARA)
}

\author{
Syafiul Muzid', Gudnanto², Noor Latifah ${ }^{3}$ \\ ${ }^{1}$ Program Studi Sistem Informasi, Fakultas Teknik, Universitas Muria Kudus \\ ${ }^{2}$ Program Studi Bimbingan dan Konseling, Fakultas Keguruan dan Ilmu Pendidikan, Universitas Muria Kudus \\ ${ }^{3}$ Program Studi Sistem Informasi, Fakultas Teknik, Universitas Muria Kudus \\ Email: ${ }^{1}$ syafiul.muzid@umk.ac.id, ${ }^{2}$ gudnanto@umk.ac.id, ${ }^{3}$ noor.latifah@umk.ac.id
}

(Naskah masuk: 29 Juni 2020, diterima untuk diterbitkan: 30 Juni 2020)

\begin{abstract}
Abstrak
Mendidik anak usia dini diperlukan pemantauan yang intensif terhadap perkembangan anak seperti saat di sekolah, perkembangan anak usia dini dapat dilihat dari aktifitas akademik maupun interaksi dengan anak lain dan guru. Informasi perkembangan setiap anak usia dini di sekolah harus selalu diinformasikan kepada orangtua. Dalam menyampaikan informasi perkembangan anak didiknya, selama ini PAUD Persada Jepara melakukannya secara manual melalui pembagian hasil belajar anak pada akhir semester. Sehingga orangtua anak kesulitan dalam memantau perkembangan anaknya secara realtime. Untuk mengatasi masalah tersebut, peneliti mengembangkan suatu sistem informasi bimbingan konseling secara online (electronic counseling) dengan menggunakan metode Waterfall untuk pengembangan sistemnya serta menggunakan pemodelan Unified Modelling Language (UML) untuk perancangan sistemnya. Penelitian ini dapat mempermudah orang tua mendapatkan informasi perkembangan anaknya dengan segera (realtime) dan mempermudah kegiatan bimbingan konseling antara orangtua dengan guru PAUD Persada secara terus menerus.
\end{abstract}

Kata kunci: e-counseling, bimbingan konseling anak, perkembangan anak usia dini

\section{DEVELOPMENT E-COUNSELING SYSTEMS FOR GUIDELINES AND COUNSELING TO EARLY CHILDHOOD DEVELOPMENT (CASE STUDY : PAUD PERSADA JEPARA)}

\begin{abstract}
Educating early childhood requires intensive monitoring of children's development such as at school, early childhood development can be seen from academic activities and interactions with other children and teachers. Information on the development of every early age child at school must always be informed to parents. In delivering information on the development of their students, PAUD Persada Jepara has been doing it manually through the distribution of children's learning outcomes at the end of the semester. So that parents have difficulty in monitoring their child's development in real time. To overcome these problems, researchers developed an online counseling information system (electronic counseling) using the Waterfall method for system development and using Unified Modeling Language (UML) modeling for the system design. This research can facilitate parents to get information on their child's development immediately (realtime) and facilitate counseling guidance activities between parents and Persada PAUD teachers continuously.
\end{abstract}

Keywords: e-counseling, childhood counseling guidance, early childhood development

\section{PENDAHULUAN}

Undang-undang nomor 20 Tahun 2003 tentang sistem pendidikan nasional, secara tegas menyatakan bahwa "Pendidikan anak usia dini adalah suatu upaya pembinaan yang ditujukan kepada anak sejak lahir sampai dengan usia enam tahun yang dilakukan melalui pemberian rangsangan pendidikan untuk membantu perkembangan jasmani dan rohani agar anak memiliki kesiapan dalam memasuki pendidikan lanjut". Pendidikan anak usia dini dapat diselenggarakan pada jalur formal dan informal. Jalur formal pendidikan anak usia dini dapat dilakukan melalui sekolah pendidikan anak usia dini (PAUD).

Mendidik anak usia dini diperlukan pemantauan yang sangat intens untuk melihat perkembangan anak tersebut dikarenakan proses tumbuhkembang yang 
sangat pesat. Saat di sekolah, perkembangan anak usia dini dapat dilihat dari aktifitas akademik maupun interaksi dengan anak lain dan guru. Tugas untuk mendorong perkembangan anak usia dini saat di sekolah adalah tugas utama guru PAUD, namun tugas ini akan beralih kepada orangtua jika anak tersebut sudah berada di rumah setelah pulang sekolah. Sehingga guru juga bertugas memberikan bimbingan dan konseling kepada setiap anak dan orangtua terkait pendidikan dan perkembangan anak. Oleh karena itu kolaborasi antara guru dan orangtua sangat penting. Setiap informasi terbaru terkait perkembangan anak harus bisa sesegera mungkin diinformasikan kepada orangtua anak agar orangtua anak dapat memberikan respon atau sikap yang sesuai.

Saat ini, banyak sekolah yang telah menerapkan teknologi informasi dan komunikasi dengan baik berkaitan dengan proses peningkatan mutu pelayanan pendidikan. PAUD Persada Jepara merupakan lembaga pendidikan yang berada di bawah naungan Yayasan Persada Mulia (YPM) Jepara berdiri sejak tahun 2007. Pada saat ini PAUD Persada memiliki siswa aktif sebanyak 180 anak. Untuk melaksanakan pendidikan dengan baik, PAUD Persada memiliki sebanyak 18 guru dan 2 tenaga administrasi. Dalam pelaksanaan pendidikan dan pemantauan perkembangan anak usia dini, PAUD Persada selalu mengajak orangtua anak secara bersama-sama mendorong anak untuk selalu berkembang dengan baik. Informasi perkembangan setiap anak selalu diinformasikan kepada orangtua.

Namun informasi perkembangan anak yang diberikan kepada orangtua selama ini hanya dilakukan secara manual yaitu guru bertemu secara tatap muka dengan orangtua anak. Apabila guru tidak dapat bertemu dengan orangtua siswa pada saatnya, seringkali ada informasi yang lupa untuk disampaikan. Informasi yang biasanya segera (realtime) diberikan kepada orangtua anak adalah apabila ada informasi yang tidak baik terkait kondisi perkembangan anak. Sedangkan informasi perkembangan yang bersifat baik hanya dapat diperoleh orangtua anak pada akhir semester melalui pembagian hasil belajar anak. Sehingga orangtua anak kesulitan dalam memantau perkembangan anaknya.

Dalam kasus ini, beberapa guru PAUD Persada menggunakan aplikasi chat Whatsapp untuk mengirimkan informasi kepada orangtua anak. Namun kelemahan penggunaan aplikasi Whatsapp adalah informasi perkembangan anak tidak dapat terintegrasikan dengan baik pada saat pembuatan buku hasil belajar anak. Sehingga memunculkan masalah baru yaitu penyampaian informasi tidak dapat didokumentasikan dengan baik.

Selain itu, Kepala Sekolah PAUD Persada sebagai penanggungjawab pelaksanaan pendidikan tentunya harus dapat memantau perkembangan anak usia dini yang menjadi siswa di PAUD Persada. Namun hal ini akan menjadi kendala apabila informasi perkembangan anak tersebut dikirimkan melalui aplikasi Whatsapp. Walaupun ada bisa menggunakan fitur grup Whatsapp, namun ada beberapa informasi perkembangan anak yang bersifat private yang hanya boleh diketahui oleh pihak sekolah dan orangtuanya siswa dan tidak boleh diketahui orang lain.

Melihat hal itu, peneliti tertarik untuk menyelesaikan masalah tersebut dengan mengembangkan suatu sistem informasi bimbingan konseling secara online (electronic counseling) untuk mempermudah orang tua mendapatkan informasi perkembangan anaknya dengan segera (realtime) dan mempermudah kegiatan bimbingan konseling antara ornagtua dengan guru PAUD Persada.

\section{PENELITIAN TERKAIT}

Beberapa penelitian lain telah dilakukan terkait dengan pengembangan sistem informasi bimbingan dan konseling. Budi menjelaskan orang tua siswa masih mengalami kesulitan dalam memantau kegiatan belajar anak mereka di sekolah sehingga setiap pertemuaan pengambilan rapot siswa di akhir semester sering terjadi keluhan dari orang tua siswa dalam keterbatasan mendapatkan informasi nilai, kehadiran maupun perilaku anak. Penelitian ini mengembangkan sistem informasi yang dapat menginput data nilai dan data absensi siswa didiknya ke dalam sistem pemantauan siswa dan memudahkan orang tua siswa untuk memantau anak mereka (Utomo, 2011).

Hermansyah dan Rini (2013) mengatakan bahwa sistem informasi monitoring dapat digunakan untuk memonitoring prestasi akademik siswa. Penelitian yang dilakukan pada SD Negeri Jati 6 Kota Tangerang menjelaskan bahwa lokasi penelitian memiliki kelemahan yang kompleks dalam memonitoring prestasi akademik siswa. Proses pengolahan data prestasi siswa yang masih manual dan belum terkomputerisasi dan penyimpanan data yang tersebar di setiap guru menyebabkan masalah pada dokumentasinya. Hasil penelitian ini adalah sistem informasi yang dapat mengelola data prestasi dan membuat laporan akumulasi nilai siswa dan aktifitas siswa.

Dengan sistem informasi monitoring studi siswa dapat mempermudah proses penilaian dan monitoring siswa sehingga permasalahan penilaian secara harian atau pertemuan yang dipegang oleh guru dapat disimpan melalui sistem. Sehingga memudahkan pembuatan nilai akhir persemester (Deni dan Agus, 2015). Sistem informasi monitoring juga dapat digunakan untuk memberikan informasi kepada orang tua/wali siswa dan pihak eksternal sehingga dapat memantau perkembangan anak (Hilma dkk, 2016). Murdianingsih (2017) menjelaskan bahwa dengan sistem monitoring perkembangan anak dapat memudahkan orangtua untuk memonitoring perkembangan siswa serta memudahkan orang tua dalam mengetahui informasi perkembangan putra- 
putrinya secara cepat tanpa menunggu pembagian raport di setiap semester.

Aplikasi e-counseling dapat digunakan untuk mengatasi siswa terisolir. Salah satu penyebab siswa terisolir diantaranya adalah kurangnya minat bersosial dan kurangnya kemampuan siswa menyesuaikan diri dengan lingkungannya. Salah satu masalah yang dimiliki oleh siswa terisolir adalah kurangnya layanan informasi pada siswa sehingga mengakibatkan semakin terasingkannya siswa dari pergaulan teman sekelasnya (Riswandha dan Maulidyah, 2017).

Dari tinjauan pustaka di atas maka peneliti tertarik untuk mengembangkan sebuah sistem informasi e-counseling untuk memudahkan memantau perkembangan anak usia dini di sekolah dimana guru nanti dapat secara realtime mengirimkan informasi perkembangan anak usia dini di PAUD Persada Jepara baik yang bersifat baik maupun tidak. Sehingga kemudahan layanan bimbingan konseling dan cepatnya informasi perkembangan anak usia dini dikirimkan ke orangtua dapat meningkatkan kualitas pendidikan di PAUD Persada Jepara dan meningkatkan daya saing dengan kompetitornya.

\section{METODOLOGI PENELITIAN}

\subsection{Metode Pengumpulan Data}

Metode pengumpulan data dilakukan untuk memperoleh data yang relevan, reliable, dan akurat. Berikut ini beberapa metode pengumpulan data yang digunakan dalam penelitian:

- Observasi dilakukan melalui pengamatan dan pencatatan objek penelitian secara langsung. Misalnya untuk mendapatkan data anak dan orangtua di PAUD Persada Jepara.

- Pengumpulan data melalui tatap muka dan tanya jawab langsung dengan sumber data dengan Kepala Sekolah di PAUD Persada Jepara.

- Studi Pustaka termasuk dalam teknik pengumpulan sumber data sekunder, yaitu sumber data yang didapatkan tidak secara langsung. Dalam hal ini studi pustaka meliputi buku-buku dan literatur terkait masalah yang sedang dibahas dan juga studi dokumentasi yaitu mengumpulkan data dari formulir atau dokumen yang digunakan selama proses perkembangan anak di sekolah.

\subsection{Metode Pengembangan Sistem}

Metode pengembangan sistem yang digunakan dalam Sistem e-Counseling untuk Bimbingan dan Konseling Perkembangan Anak Usia Dini adalah model waterfall yaitu model pengembangan yang menggambarkan secara sistematis dan terurut meliputi tahapan analisa kebutuhan sistem (requirement analysist), perancangan sistem (system design), pengembangan sistem (system development), pengujian sistem (integration and testing) dan penyerahan sistem ke pengguna dan perawatan sistem (operation and maintenance). Model ini merupakan model pengembangan sistem yang paling banyak digunakan dikarenakan tahapannya yang teratur setiap langkahnya (Pressman, 2002).

\subsection{Analisa Sistem}

Berdasarkan analisa dari masalah yang terjadi maka aktor yang terlibat dalam Sistem $e$-Counseling untuk Bimbingan dan Konseling Perkembangan Anak Usia Dini adalah sebagai berikut:

- Kepala Sekolah merupakan aktor utama yang bertugas mengelola data Guru, data Tata Usaha (TU), data siswa dan orangtuanya serta dapat memantau dan melihat laporan perkembangan dan hasil belajar anak.

- Guru adalah aktor yang bertugas mengunggah data perkembangan anak di sekolah melalui sistem dengan menggunakan fitur foto atau video dari aktivitas anak serta mengelola raport hasil belajar anak.

- Tata Usaha (TU) sebagai aktor yang bertugas mengelola data siswa dan data kelas dan wali kelasnya.

- Orangtua sebagai aktor yang dapat melihat perkembangan anaknya di sekolah berdasarkan data yang diunggah oleh Guru dan berkonsultasi dengan Guru melalui sistem.

Aktor-aktor tersebut melakukan beberapa aktivitas dalam Sistem e-Counseling untuk Bimbingan dan Konseling Perkembangan Anak Usia Dini ditunjukkan pada Tabel 1.

Tabel 1. Proses bisnis yang digunakan dalam sistem

\begin{tabular}{|c|l|l|l|}
\hline No & Proses Bisnis & \multicolumn{1}{|c|}{ Aktor } & Proses Bisnis \\
\hline 1 & $\begin{array}{l}\text { Kelola data } \\
\text { guru }\end{array}$ & $\begin{array}{l}\text { Kepala } \\
\text { sekolah }\end{array}$ & $\begin{array}{l}\text { Mengelola } \\
\text { data guru }\end{array}$ \\
\hline 2 & Kelola data TU & $\begin{array}{l}\text { Kepala } \\
\text { sekolah }\end{array}$ & $\begin{array}{l}\text { Mengelola } \\
\text { data Tata } \\
\text { Usaha }\end{array}$ \\
\hline 4 & $\begin{array}{l}\text { Kelola data } \\
\text { siswa } \\
\text { Kelola data } \\
\text { kelas }\end{array}$ & TU & $\begin{array}{l}\text { Mengelola } \\
\text { data siswa }\end{array}$ \\
\hline 5 & $\begin{array}{l}\text { Kelola data } \\
\text { perkembangan } \\
\text { anak } \\
\text { data kelas }\end{array}$ \\
\hline 6 & $\begin{array}{l}\text { Kelola raport } \\
\text { hasil belajar }\end{array}$ & $\begin{array}{l}\text { Mencatat data } \\
\text { perkembangan } \\
\text { harian per } \\
\text { anak }\end{array}$ \\
\hline 7 & $\begin{array}{l}\text { Lihat data } \\
\text { perkembangan } \\
\text { anak }\end{array}$ & $\begin{array}{l}\text { Membuat } \\
\text { laporan raport } \\
\text { hasil belajar } \\
\text { anak }\end{array}$ \\
\hline 8 & $\begin{array}{l}\text { Lihat raport } \\
\text { hasil belajar }\end{array}$ & $\begin{array}{l}\text { Orangtua } \\
\text { melihat hasil } \\
\text { perkembangan } \\
\text { anak }\end{array}$ \\
\hline 9 & Orangtua & $\begin{array}{l}\text { Orangtua } \\
\text { melihat hasil } \\
\text { perkembangan } \\
\text { anak }\end{array}$ \\
\hline
\end{tabular}




\begin{tabular}{|l|l|l|l|}
\hline 10 & Kirim pesan & $\begin{array}{l}\text { Guru \& } \\
\text { Orangtua }\end{array}$ & $\begin{array}{l}\text { Guru \& } \\
\text { Orangtua } \\
\text { saling } \\
\text { mengirim } \\
\text { pesan }\end{array}$ \\
\hline
\end{tabular}

\section{HASIL DAN PEMBAHASAN}

\subsection{Perancangan Sistem}

Setelah proses analisa yang telah dilakukan kemudian dilanjutkan tahap perancangan sistem menggunakan diagram Unified Modelling Language (UML). Unified Modeling Language (UML) adalah suatu bahasa permodelan untuk membangun perangkat lunak yang dibangun dengan menggunakan teknik pemrograman berorientasi objek. Desain sistem terdiri atas perancangan antarmuka, estetika, konten, navigasi, arsitektur, komponen. Rancang bangun dalam penelitian ini menggunakan perancangan berorientasi objek (UML) (Podeswa, 2006).

Diagram yang dihasilkan pada proses analisa adalah diagram usecase, diagram class, diagram sekuen, diagram aktivitas, dan diagram status. Diantara diagram-diagram tersebut adalah diagram usecase. Diagram usecase adalah diagram yang mendeskripsikan interaksi antara satu atau lebih aktor dengan sistem informasi yang akan dibuat (Sukamto dan Shalahuddin, 2016).

Usecase sistem digunakan untuk menggambarkan proses sistem yang akan dikembangkan secara lebih jelas dan mudah dipahami. Berdasarkan analisa, maka ditentukan jumlah usecase yang digunakan dalam Sistem $e$ Counseling untuk Bimbingan dan Konseling Perkembangan Anak Usia Dini adalah sebanyak 9 (sembilan) buah usecase dan 4 (empat) aktor. Lebih jelasnya dapat dilihat pada Gambar 1.

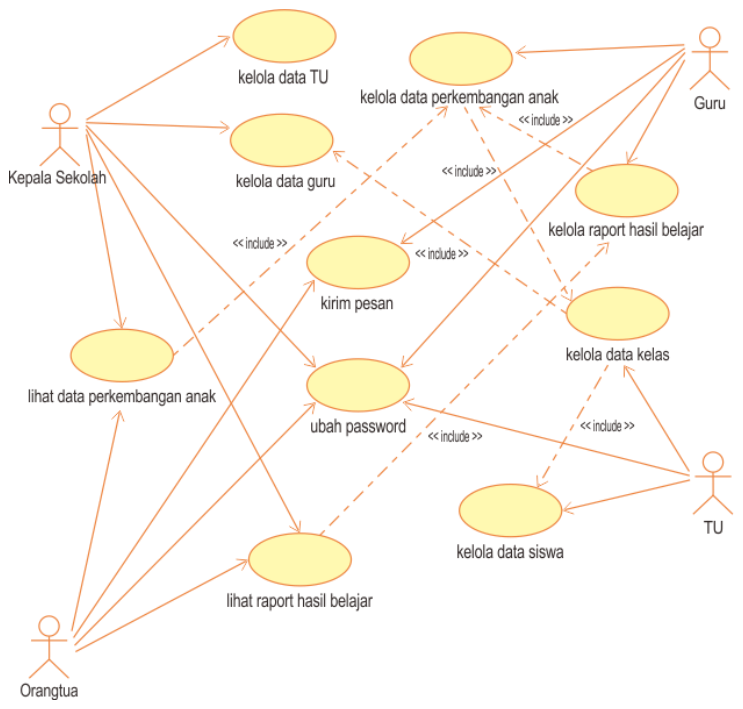

Gambar 1. Usecase sistem e-counseling untuk bimbingan dan konseling perkembangan anak usia dini
Dalam Gambar 1, setiap aktor sistem memiliki hak akses yang berbeda-beda terhadap usecase yang ada. Kepala Sekolah mengakses sebanyak 5 (lima) usecase, Guru mengakses sebanyak 4 (empat) usecase dan Oangtua siswa dapat mengakses sebanyak 4 (empat) usecase, sedangkan TU dapat mengakses sebanyak 3 (tiga) usecase. Hal ini dikarenakan aktivitas yang berbeda dari setiap aktor.

\subsection{Perancangan Basisdata}

Data-data dari Sistem e-Counseling untuk Bimbingan dan Konseling Perkembangan Anak Usia Dini yang dikembangkan diolah menggunakan software basis data MySQL. Dalam basis data tersebut dibuat sebanyak 12 (dua belas) tabel yang dihasilkan. Adapun tabel dan relasi tabelnya dari Sistem e-Counseling untuk Bimbingan dan Konseling Perkembangan Anak Usia Dini dapat dilihat pada gambar dibawah ini

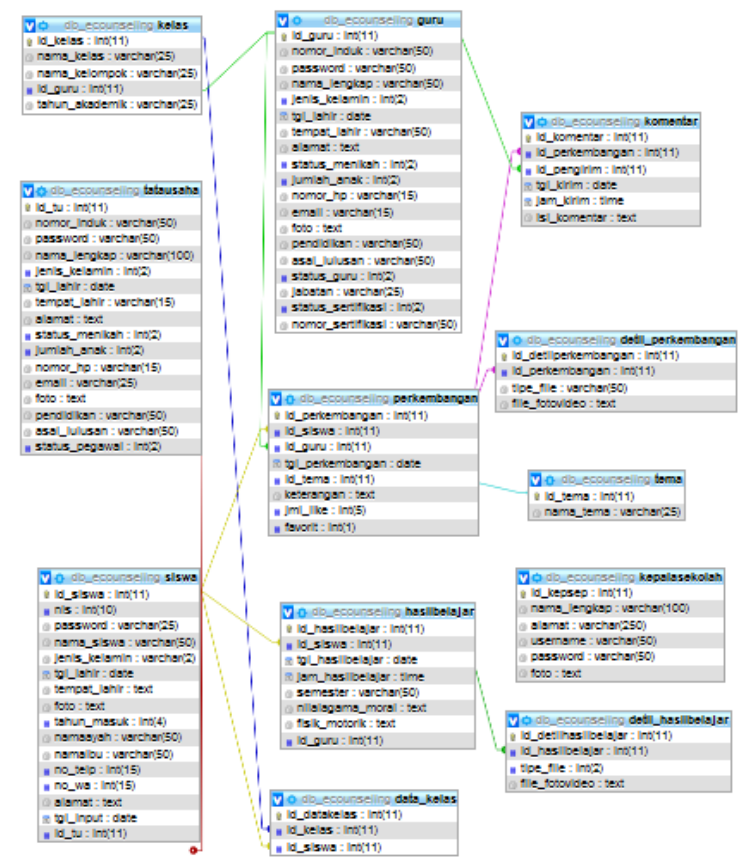

Gambar 2. Relasi tabel dalam basisdata sistem $e$ counseling untuk bimbingan dan konseling perkembangan anak usia dini

\subsection{Hasil Sistem}

Hasil analisa dan perancangan yang telah dilakukan kemudian dilakukan pengembangan Sistem e-Counseling untuk Bimbingan dan Konseling Perkembangan Anak Usia Dini menggunakan bahasa pemrograman PHP dan database MySQL. Berikut ini beberapa antarmuka dari sistem yang dibangun:

- Tampilan kelola data guru

Tampilan ini digunakan untuk mengelola data guru yang mengajar di PAUD Persada Jepara. 


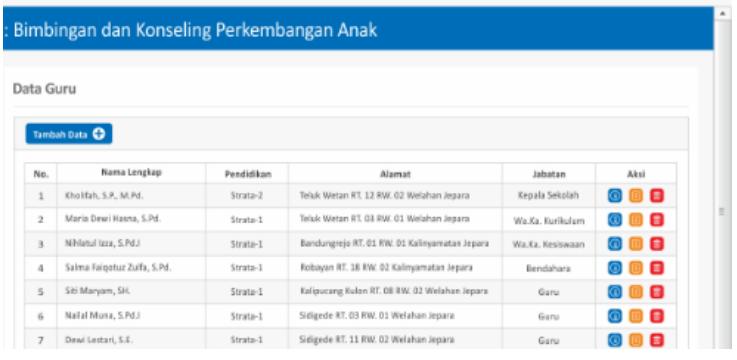

Gambar 3. Tampilan data guru pada sistem e-counseling

Sedangkan Gambar 4 menunjukkan tampilan pengelolaan data kelas dan wali kelas. Pada menu ini, penambahan data kelas meliputi nama kelas dan nama kelompok. Kelas yang dimaksud adalah pengkategorian siswa. Kelas A digunakan untuk siswa usia antara 3 sampai 4 tahun, sedangkan kelas B digunakan untuk siswa yang berusia 5 sampai 6 tahun. Nama kelompok adalah pembagian kelas kategori. Setiap kelompok diisi sekitar 10 sampai 12 siswa. Hal ini dikarenakan aturan standar beban mengajar guru pada sekolah anak usia dini. Pengelolaan data kelas dilakukan oleh bagian Tata Usaha.

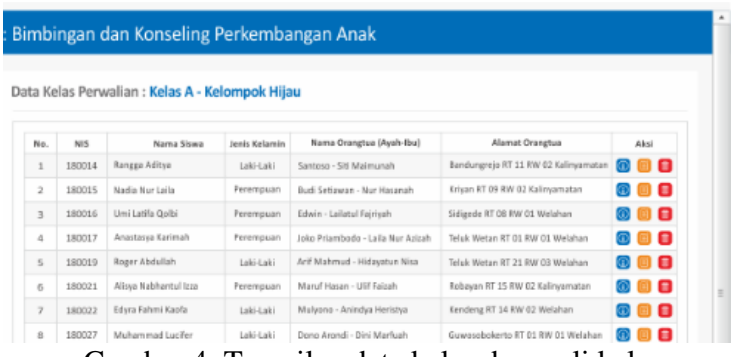

Gambar 4. Tampilan data kelas dan wali kelas

Setiap Guru diwajibkan untuk mengisi data perkembangan siswa dalam setiap pertemuannya. Hal ini bertujuan sebagai informasi yang realtime yang bisa diakses langsung oleh orangtua siswa setiap harinya untuk melihat perkembangan anaknya. Untuk melengkapi data perkembangan yang dimasukkan, Guru dapat menambahkan file berupa foto atau video yang menunjukkan informasi perkembangan si anak tersebut seperti pada Gambar 5.

\section{: Bimbingan dan Konseling Perkembangan Anak}

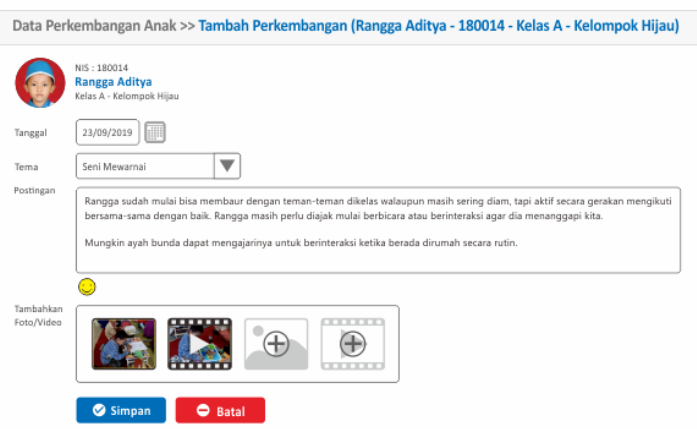

Gambar 5. Tampilan menu tambah data perkembangan anak yang bisa dilengkapi dengan foto atau video.
Gambar 6 menunjukkan tampilan data perkembangan anak yang dapat dikomentari oleh orangtua siswa dan guru. Fitur ini ditujukan agar orangtua dan guru bisa dapat secara langsung (realtime) berinteraksi tentang perkembangan siswa tersebut.

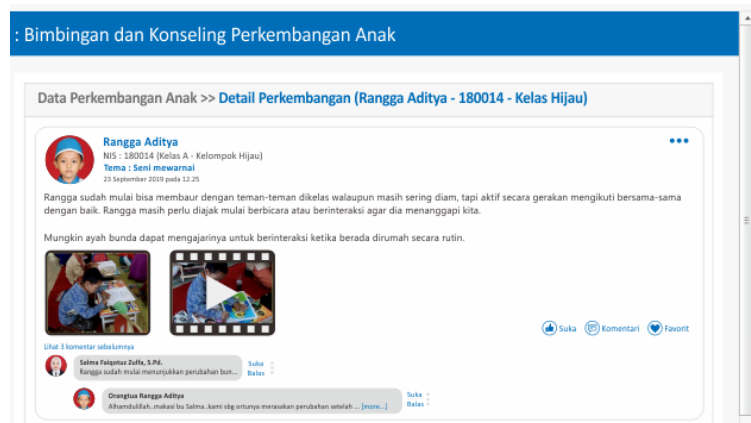

Gambar 6. Tampilan fitur komentar antara guru dan orangtua siswa terkait data perkembangan anak

Hasil informasi perkembangan siswa pada setiap pembelajaran dapat digunakan oleh guru secara mudah ketika membuat raport hasil belajar pada akhir semester. Pada Gambar 7 menunjukkan fitur pembuatan raport hasil belajar oleh Guru, dimana guru dapat menggunakan informasi data perkembangan baik foto atau video yang sudah ada didalam sistem pada semester yang sedang berlangsung.

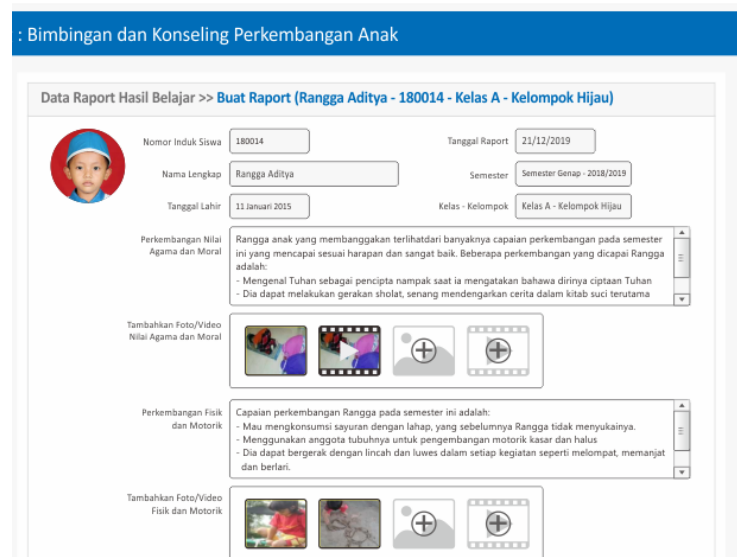

Gambar 7. Tampilan pembuatan raport hasil belajar semester

Raport hasil belajar yang telah dibuat oleh Guru dapat dilihat secara langsung oleh orangtua siswa melalui sistem karena orangtua siswa juga diberi hak akses kedalam sistem.

Dengan menggunakan Nomor Induk Siswa (NIS) sebagai username dan password yang telah diberikan, orangtua dapat secara langsung (realtime) melihat raport hasil belajar jika sudah dibuat oleh Guru. Raport digital ini dapat diisi dengan informasi foto maupun video terkait perkembangan siswa. Namun raport fisik juga tetap dicetak melalui sistem yang nantinya akan dilegalisir dan diserahkan kepada orangtua siswa sebagai informasi hasil belajar siswa 
setiap semesternya. Tampilan raport hasil belajar digital yang dapat diakses oleh orangtua siswa dapat dilihat pada Gambar 8.

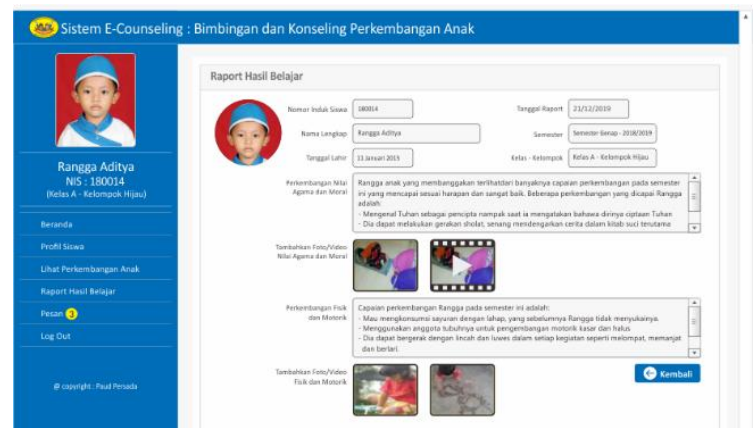

Gambar 8. Tampilan raport hasil belajar siswa yang dapat diakses oleh orangtua secara realtime.

\section{KESIMPULAN}

Berdasarkan implementasi dan pengujian terhadap penelitian ini maka dapat terdapat beberapa hal yang dapat disimpulkan. Kesimpulan dari penelitian ini adalah sebagai berikut:

- Penelitian ini menghasilkan sebuah Sistem $e$ Counseling untuk Bimbingan dan Konseling Perkembangan Anak Usia Dini yang dapat digunakan untuk memantau perkembangan anak usia dini pada PAUD Persada Jepara secara realtime.

- Sistem e-Counseling untuk Bimbingan dan Konseling Perkembangan Anak Usia Dini dapat digunakan sebagai media bimbingan konseling antara orangtua dan guru terkait perkembangan anak usia dini.

- Sistem ini juga membantu dan memudahkan guru dalam membuat buku hasil belajar setiap akhir semester secara otomatis dikarenakan data perkembangan anak disimpan ke dalam sistem setiap saat secara berkesinambungan.

\section{UCAPAN TERIMA KASIH}

Terima kasih kami haturkan kepada Lembaga Penelitian dan Pengabdian pada Masyarakat Universitas Muria Kudus atas pembiayaan penelitian ini melalui Dana Hibah Penelitian Dosen Tahun 2018 serta pihak-pihak yang membantu terlaksananya penelitian dengan baik sehingga dapat diselesaikan dan dipublikasikan.

\section{DAFTAR PUSTAKA}

DENI, M., AGUS, P.U., 2015, Sistem Informasi Monitoring Studi Siswa SMA Berbasis Kurikulum Nasional 2013, Jurnal Dinamika Informatika, Vol.6 No.2, Oktober 2014, Universitas Stikubank Semarang, [ejournal], Tersedia di: < https://www.unisbank.ac.id/ojs/index.php/ft i2/article/view/3806> [Diakses 21 Februari 2020].

HERMANSYAH, RINI, S.P., 2013, Sistem Informasi Monitoring Prestasi Akademik dan Aktifitas Siswa Sekolah Dasar Berbasis Web, Jurnal Sisfotek Global, Vol.3 No.2, September, 2013, STMIK Bina Sarana Global, Tangerang, [e-journal], Tersedia di: <http://journal.stmikglobal.ac.id/index.php/ sisfotek/article/view/29>, [Diakses 21 Februari 2020].

HILMA, Y.S.F., EVA, R., DESI,I.R., 2016, Rancang Bangun Sistem Informasi Pemantauan Perkembangan Anak di Yayasan Bina Autis Mandiri Palembang Berbasis Web dan SMS Gateway, Program Studi Sistem Informasi, STMIK GI Multi Data Palembang, Palembang, [e-book], Tersedia di: < http://eprints.mdp.ac.id/940/> [Diakses 21 Februari 2020].

MURDIANINGSIH, L., 2017, Sistem Informasi Monitoring Perkembangan Siswa di TKIT Abu Bakar Ash Shidiq Pati Berbasis Web Responsif, Program Studi Sistem Informasi Fakultas Teknik Universitas Muria Kudus, Kudus, [e-book], Tersedia di: < https://eprints.umk.ac.id/8249/ >, [Diakses 9 Juni 2019]

PODESWA, H., 2006, UML for the IT Business Analyst: A Practical Guide to ObjectOriented Requirements Gathering, Boston, Thomson Course Technology PTR.

PRESSMAN, R., 2002, Software Engineering : Practical Approach, New York, WembleyHills.

RISWANDHA, M.N., MAULIDYAH, N., 2017, Aplikasi E-Counseling dalam Pemanfaatan Layanan Bimbingan dan Konseling untuk Mengatasi Siswa Terisolir menggunakan Metode Backward Chaining (Studi Kasus : di SMP Negeri 2 Bangil), Jurnal LINK, Vol. 26 No. 1, Februari, 2017, Fakultas Ilmu Komputer Universitas Narotama, Surabaya, [e-journal], Tersedia di: <http:// http://link.narotama.ac.id>, [Diakses 21 Februari 2020]

SUKAMTO, R. A., SHALAHUDDIN, M., 2016, Rekayasa Perangkat Lunak Terstruktur dan Berorientasi Objek. Bandung: Informatika Bandung.

UTOMO, B., 2011, Sistem Pemantauan Siswa Sekolah Berbasis Web (Studi Kasus : Pondok Pesantren Darul Muttaqien), Jurnal JOM Program Studi Ilmu Komputer Fakultas Matematika dan Ilmu Pengetahuan Alam Universitas Pakuan, Bogor, [ejournal], Tersedia di: < https://jom.unpak.ac.id/index.php/ilkom/art icle/view/493> [Diakses 9 Juni 2019] 